\title{
Effect of Temperature on Thermodynamic Properties of Protic Ionic Liquids: 2-Hydroxy Ethylammonium Lactate (2-HEAL) + Short Hydroxylic Solvent
}

\author{
S. Barros ${ }^{1}$, R.S. Andrade ${ }^{1,2}$, and M. Iglesias ${ }^{*}, 1$ \\ ${ }^{1}$ Departamento de Engenharia Química, Universidade Federal da Bahia, Salvador, Brasil \\ ${ }^{2}$ Centro de Estudos em Tecnologia, Energia e Sustentabilidade - CETENS, Universidade Federal do Recôncavo da Bahia, \\ Feira de Santana, Brasil \\ E-mail: *miguel.iglesias@ufba.br
}

Received 03 April 2017, Revised 20 March 2018, Accepted 23 March 2018

\begin{abstract}
In this study, we have synthesized the protic ionic liquid 2-hydroxy ethylammonium lactate (2-HEAL), and investigated its volumetric and acoustic behavior into different hydroxylic media (water, methanol and ethanol) at the temperature 288.15-323.15 K and atmospheric pressure. Total solubility of the ionic liquid into these solvents was observed at this range of temperature. Apparent molar volume and apparent molar isentropic compressibility values have been computed from the experimental data and fitted to a temperature dependent Redlich-Mayer equation. From these correlations, the limiting infinite dilution values of the apparent magnitudes have also been computed. Derived magnitudes such as isobaric expansibility and isothermal coefficient of pressure excess molar enthalpy were computed due to their importance in the study of specific molecular interactions among the ions and covalent molecules enclosed into mixtures. The measured experimental data were used to test the accuracy of prediction of different models (Mchaweh-Nasrifar-Moshfeghian model (MNM model) and the modified Heller temperature dependent equation (MHE) for density and Collision Factor Theory (CFT) for ultrasonic velocity). The obtained results indicate that ionic liquid interactions in water are weaker than in the studied alcoholic solutions, as previously observed in analogous protic ionic liquids.
\end{abstract}

Keywords: Protic ionic liquid; thermodynamic properties; hydroxylic compounds; theoretical models.

\section{Introduction}

Ionic liquids (ILs) have huge potential as neoteric solvents for a wide array of academic and industrial applications. The desired thermodynamic properties of these ionic compounds should be attained by tuning the molecular functional groups enclosed into the structures of anions and cations, as well as, by creating adequate mixtures of ionic liquids or ionic liquids into current covalent solvents. An ionic liquid is a salt in which the enclosed anions and cations are softly structured and coordinated due to steric hindrance effects, which results in these chemicals showing liquid state below $100^{\circ} \mathrm{C}$. It is common to gather at least one ion has one or more delocalized electronic charge, and different organic chains into the ionic liquid, which prevents the formation of a stable ionic crystal lattice and afterwards solid state at laboratory conditions. Since the first report on stable ionic liquids, many ionic liquids have been investigated with promising potential applications as clean solvents, catalysts for green processes, photochemistry, electro synthesis and other applications as lubricants, separation agents, membrane fuel cells, electrolytes for batteries, new strategies for cheaper solar cells or cleaning applications in processes of minimization of $\mathrm{CO}_{2} / \mathrm{SO}_{2}$ emissions. Although its total environmental safety is being widely discussed, we should consider them as "green compounds" anyway due to their negligible vapor pressure if compared to traditional volatile organic solvents widely used in chemical and mechanical industry. Other core benefits of ionic liquids are their favorable solvation behaviour, large liquid state range, low melting point, chemical stability in oxidizing atmosphere and high ionic conductivity, which open new possibilities in various industrial fields. Different review papers highlight the huge potential of these taylor-made solvents [1-7]. Due to these facts, these kind of compounds are finding rising relevance in the last few years, just into academic and industrial sectors. Based on their chemical behavior, ILs can be divided in two main groups: aprotic (AILs) and protic (PILs) ionic liquids. The structure of AILs is mainly based on bulky organic cations with long alkyl chain ends and a large variety of traditional inorganic anions. The mainstream scientific effort in terms of thermodynamic studies and potential applications is almost confined to salts of organic amines such as substituted imidazolines, alkyl pyridiniums and trialkylamines being the counter ions, mainly, weak nucleophilic inorganic anions or more or less common inorganic anions. A simple analysis of open literature proves that the number of publications on PILs characterization and applications is significantly lower.

The studied protic ionic liquid in this paper, 2-hydroxy ethylammonium lactate (2-HEAL), belongs to a newly designed family of PILs, enclosing substituted amines, as cations and organic deprotonated acids with different numbers of carbon atoms, as anions. Both ionic structures into the protic ionic liquid are of organic nature and gather a relatively low molar mass. The potential environmental impact of these new PILs was analyzed and is smaller than 
the impact of AILs [8-12], which shown practically no biodegradation. The main merit of this kind of PILs is to obtain sufficient steric hindrance with a reduced number of atoms without complex structures or potential hazard molecular groups. In the last few years, the authors developed different works on potential applications and thermodynamic behavior of these compounds [13-22] and this work is a new contribution in this aim. In spite of their relevance, and the rising number of scientific articles related to ILs in the last few years, there is a scarcity of thermodynamic information of these compounds and their key mixtures. These data are fundamental to develop and design new equipment and processes enclosing ionic liquids, as well as, test new models for physical properties or phase equilibria prediction. The scarce of disposable prediction methods, suggests the need of increasing research effort in experimental studies of thermodynamic properties evolving this kind of compounds, as well as, developing and refining new theoretical prediction procedures. Hydroxylic mixtures containing this new type of ionic liquids gather special relevance due to their homogeneous character and, in general terms, the PILs huge tolerance for being dissolved into polar media (acids, alcohols, water), contrary to the common character of AILs, as observed in open literature. In this context, our aim is to study two key physical properties (density and ultrasonic velocity) of 2-hydroxy ethyl ammonium lactate (2-HEAL) and its solutions with short hydroxylic solvents (water, methanol, and ethanol) over a wide range of temperature at atmospheric pressure. As far as we know, no information related with this new ionic liquid (2-HEAL) is available about its phase behavior or mixing trend or temperature dependence on mixing until now.

The measured experimental data were used to test the capability of the Mchaweh-Nasrifar-Moshfeghian model [23-24], the modified Heller equation [25] for density and the Collision Factor Theory (CFT) [26] for ultrasonic velocity prediction.

\section{Experimental}

\subsection{Preparation of the Protic Ionic Liquid}

Ethanolamine better than $98.0 \%$ was placed in a three necked flask all-made-in-glass equipped with a reflux condenser, a PT-100 temperature sensor for controlling temperature and a dropping funnel. The flask was mounted in an ice bath. The lactic acid $(>98.0 \%)$ was added dropwise to the flask under stirring with a magnetic bar. Stirring was continued for $24 \mathrm{~h}$ at laboratory temperature, in order to obtain a final viscous yellow liquid. No solid crystals or precipitation was noted when the liquid sample was purified or was stored at freeze temperature for a few months. Detailed description of laboratory procedure should be found in earlier papers $[15,16]$. The molar mass, experimental data at standard condition for 2-HEAL and the other solvents are shown in Table 1, as well as, disposable data into open literature [27-32].

\subsection{Spectroscopic Test}

In order to ensure the ionic structure of 2-HEAL, FT-IR spectrum was taken by a Jasco FT/IR 680 plus model IR spectrometer, using a $\mathrm{NaCl}$ disk. As expected, characteristics signals were showed as the broad band in the $3500-2400 \mathrm{~cm}^{-}$ 1 range (characteristic ammonium structure, enclosing the $\mathrm{OH}$ stretching vibration), the broad band centered at 1600 $\mathrm{cm}^{-1}$ (combined band of the carbonyl stretching and $\mathrm{N}-\mathrm{H}$ plane bending vibrations), and two characteristic bands at
$3500-2400 \mathrm{~cm}^{-1}$ for $\mathrm{NH}_{3}{ }^{+}+\mathrm{OH}^{-}$and other wide band at 1600 $\mathrm{cm}^{-1}$ for $\mathrm{COO}^{-}+\mathrm{N}-\mathrm{H}$ plane bend.

Table 1. Comparison of experimental with literature data for pure compounds at $298.15 \mathrm{~K}$ and other relevant information.

\begin{tabular}{|c|c|c|c|c|c|}
\hline & $\begin{array}{c}\text { Molar } \\
\text { Mass } \\
\left(\mathrm{gmol}^{-1}\right) \\
\end{array}$ & $\begin{array}{c}\text { Exp. } \\
\text { Dens. } \\
\left(\mathrm{gcm}^{-3}\right)\end{array}$ & $\begin{array}{c}\text { Lit. } \\
\text { Dens. } \\
\left(\mathrm{gcm}^{-3}\right)\end{array}$ & $\begin{array}{c}\text { Exp. Ultras. } \\
\text { Velocity } \\
\left(\mathrm{ms}^{-1}\right) \\
\end{array}$ & $\begin{array}{c}\text { Lit. Ultras. } \\
\text { Velocity } \\
\left(\mathrm{ms}^{-1}\right)\end{array}$ \\
\hline 2-HEAL & 151.161 & 1.20156 & n. a. & 1865.53 & n. a. \\
\hline Water & 18.015 & 0.99704 & $\begin{array}{c}0.99705^{\mathrm{a}} \\
0.99712^{\mathrm{b}} \\
0.997047^{\mathrm{c}}\end{array}$ & 1496.89 & $1496.687^{d}$ \\
\hline Methanol & 32.042 & 0.78646 & $\begin{array}{l}0.78637^{\mathrm{a}} \\
0.78664^{\mathrm{b}}\end{array}$ & 1101.58 & $1102^{\mathrm{e}}$ \\
\hline Ethanol & 46.070 & 0.78589 & $\begin{array}{l}0.78493^{\mathrm{a}} \\
0.78730^{\mathrm{b}}\end{array}$ & 1143.12 & $1143^{\mathrm{f}}$ \\
\hline
\end{tabular}

${ }^{\mathrm{a}}[27],{ }^{\mathrm{b}}[28],{ }^{\mathrm{c}}[29],{ }^{\mathrm{d}}[30],{ }^{\mathrm{e}}[31],{ }^{\mathrm{f}}[32]$

\subsection{Physical Properties Equipment}

The pure protic ionic liquid 2-HEAL was stored in sun light protected form, constant humidity, nitrogen atmosphere and ambient temperature. Usual manipulation in our experimental work and a strong purification of water pollution before use, due to the hygroscopic character of these compounds, were applied, as explained above. The densities and ultrasonic velocities of pure ionic components were measured with an Anton Paar DSA-5000M vibrational tube densimeter and sound analyzer, with a resolution of $10^{-}$ $5 \mathrm{gcm}^{-3}$ and $1 \mathrm{~ms}^{-1}$. Apparatus calibration was performed periodically in accordance with vendor instructions using a double reference (Millipore quality water and ambient air), before measurements (triple measurement at each composition). Each mixture was prepared with a known mass of both ionic liquids, by weighing with a precision $( \pm 5$ $10^{-5} \mathrm{~g}$ ) device (GRAM-VXI Serie Analytical Balance). The mixtures were sealed in the vials with an aluminum cap and a rubber plug, the empty space in the vials being minimized, in order to avoid atmospheric water pollution. Accuracy in the temperature of measurement was better than $\pm 10^{-2} \mathrm{~K}$ by a control device that apply the Peltier principle to maintain isothermal conditions during the measurements into the density and ultrasonic velocity cells.

\section{Results and Discussion \\ 3.1 Physical Properties Correlation}

The density and ultrasonic velocity of the mixtures were correlated as a function of composition as follows:

$P=\sum_{i=0}^{N}\left(\sum_{j=0}^{M} B_{i j} T^{j}\right) x^{i}$

where $\mathrm{P}$ is density $\left(\mathrm{gcm}^{-3}\right)$ or ultrasonic velocity $\left(\mathrm{ms}^{-1}\right), \mathrm{x}$ is the molar fraction and $\mathrm{B}_{\mathrm{ij}}$ fitting parameters. $\mathrm{N}$ and $\mathrm{M}$ stand for the extension of the mathematical series which were optimized by means of the Bevington test. Densities and ultrasonic velocity are given as Supplementary Material (Table ST1) for these mixtures. The fitting parameters were obtained by the unweighted least squared method applying a fitting Marquardt algorithm. The root mean square deviations were computed using Eq. (2), where $\mathrm{z}$ is the value of the physical property, and $\mathrm{n}_{\mathrm{DAT}}$ is the number of experimental data.

$\sigma=\left(\frac{\sum_{i=1}^{n_{D A T}}\left(z_{e x p}-z_{p r e d}\right)^{2}}{n_{D A T}}\right)^{1 / 2}$ 
Table 2. Fitting parameters of Eq. 1 and root mean square deviations $(\sigma)$ for density and ultrasonic velocity for 2$H E A L+($ water, methanol or ethanol) at $288.15-323.15 \mathrm{~K}$.

\begin{tabular}{|c|c|c|c|c|c|c|}
\hline & \multicolumn{2}{|c|}{ 2-HEAL+water } & \multicolumn{2}{|c|}{ 2-HEAL+methanol } & \multicolumn{2}{|c|}{ 2-HEAL+ethanol } \\
\hline & $\begin{array}{c}\rho \\
/\left(\mathrm{gcm}^{-3}\right) \\
\end{array}$ & $\begin{array}{c}\mathrm{u} \\
/\left(\mathrm{ms}^{-1}\right) \\
\end{array}$ & $\begin{array}{c}\rho \\
/\left(\mathrm{gcm}^{-3}\right) \\
\end{array}$ & $\begin{array}{c}\mathrm{u} \\
/\left(\mathrm{ms}^{-1}\right) \\
\end{array}$ & $\begin{array}{c}\rho \\
/\left(\mathrm{gcm}^{-3}\right) \\
\end{array}$ & $\begin{array}{c}\mathrm{u} \\
/\left(\mathrm{ms}^{-1}\right)\end{array}$ \\
\hline $\mathrm{B}_{00}$ & 1.4062 & 4261.5130 & 1.4123 & 4258.0162 & 1.3963 & 4202.4500 \\
\hline $\mathrm{B}_{01}$ & $-7.5692 \mathrm{E}-4$ & -13.1538 & $-8.0499 \mathrm{E}-4$ & -13.1403 & $-6.9508 \mathrm{E}-4$ & -12.7651 \\
\hline $\mathrm{B}_{02}$ & $2.3448 \mathrm{E}-7$ & 0.0172 & $3.1202 \mathrm{E}-7$ & 0.0172 & $1.3208 \mathrm{E}-7$ & 0.0165 \\
\hline $\mathrm{B}_{10}$ & 2.4859 & 3280.0904 & -0.1227 & -1874.5207 & -1.2266 & -8529.9010 \\
\hline $\mathrm{B}_{11}$ & -0.0130 & -47.2554 & $4.9278 \mathrm{E}-4$ & 9.3821 & 7.2073E-3 & 52.2669 \\
\hline $\mathrm{B}_{12}$ & $1.9619 \mathrm{E}-5$ & 0.1032 & $-8.0009 \mathrm{E}-7$ & -0.0140 & $-1.2035 \mathrm{E}-5$ & -0.0845 \\
\hline $\mathrm{B}_{20}$ & -14.0491 & -35348.2720 & -0.3252 & -20403.1907 & 4.2115 & 9618.8388 \\
\hline $\mathrm{B}_{21}$ & 0.0719 & 421.5952 & $-9.9892 \mathrm{E}-4$ & 132.5455 & -0.0294 & -64.3382 \\
\hline $\mathrm{B}_{22}$ & $-1.082888 \mathrm{E}-4$ & -0.8748 & $1.0753 \mathrm{E}-6$ & -0.2139 & $4.8512 \mathrm{E}-5$ & 0.1081 \\
\hline $\mathrm{B}_{30}$ & 23.8768 & 41728.0777 & 0.5225 & 54630.1540 & -6.6970 & 8963.4981 \\
\hline $\mathrm{B}_{31}$ & -0.120341 & -790.4099 & $2.4908 \mathrm{E}-3$ & -354.7822 & 0.0460 & -57.1642 \\
\hline $\mathrm{B}_{32}$ & $1.8001 \mathrm{E}-4$ & 1.7962 & $-3.2738 \mathrm{E}-6$ & 0.5644 & $-7.6403 \mathrm{E}-5$ & 0.0768 \\
\hline $\mathrm{B}_{40}$ & -13.0026 & 23371.4725 & -0.4928 & -50701.1500 & 3.2233 & -28705.8081 \\
\hline $\mathrm{B}_{41}$ & 0.0643 & 451.7916 & $-1.6284 \mathrm{E}-3$ & 326.5170 & -0.0231 & 186.1021 \\
\hline $\mathrm{B}_{42}$ & $-9.5661 \mathrm{E}-5$ & -1.3287 & $1.8730 \mathrm{E}-6$ & -0.5130 & $3.8276 \mathrm{E}-5$ & -0.2829 \\
\hline $\mathrm{B}_{40}$ & & -39551.0347 & & 16210.3504 & & 16709.3748 \\
\hline $\mathrm{B}_{41}$ & & 0.0000 & & -104.0916 & & -108.1764 \\
\hline $\mathrm{B}_{42}$ & & 0.2535 & & 0.1599 & & 0.1671 \\
\hline$\sigma$ & $3.482 \mathrm{E}-3$ & 2.162 & $1.667 \mathrm{E}-3$ & 0.888 & $1.291 \mathrm{E}-3$ & 2.281 \\
\hline
\end{tabular}

The fitting parameters and deviations are gathered in Table 2. The measurements show the progressive diminution of density and ultrasonic velocity when composition of the protic ionic liquid decreases. This tendency is observed at each mixture. As example, in Figure 1 the trend of temperature for 2-HEAL+water is showed for density, ultrasonic velocity and isentropic compressibility (computed by Laplace-Newton equation). It is important to point out as the mixture 2-HEAL+water shows a maximum of ultrasonic velocity at every studied temperature from 0.33 to 0.44 molar fraction. For alcohols, the evolution of the magnitudes is the same in terms of composition, but showing increasing ultrasonic velocities for decreasing temperatures, contrary to water. The isentropic compressibilities of aqueous mixture are showed at Figures 1c. It shows a curious tendency as observed in this figure and into the zoom gathered. This kind of tendencies, as observed in others aqueous mixtures of different protic ionic liquids [14, 18, 21], express into this very narrow interval of concentration where the compressibility isotherms cross one another, points to formation of a clathrate-like structure with the stoichiometry corresponding to the concentration at which the crossing occurs. The structure is relatively temperature-resistant and, then, the rigidity of mixture is independent of temperature. Attending to our results, this structure for water is created at molar fraction 0.935. Different authors have suggested this molecular structure for ionic liquid into different solvents based on calorimetric or instrumental techniques, but ultrasonic techniques are appropriate too, in order to identify this phenomenon. Analysis of isentropic compressibilities for alcoholic mixtures shows progressive diminution on temperature and 2-HEAL composition but not independent trend of temperature, as could be expected.

(a)

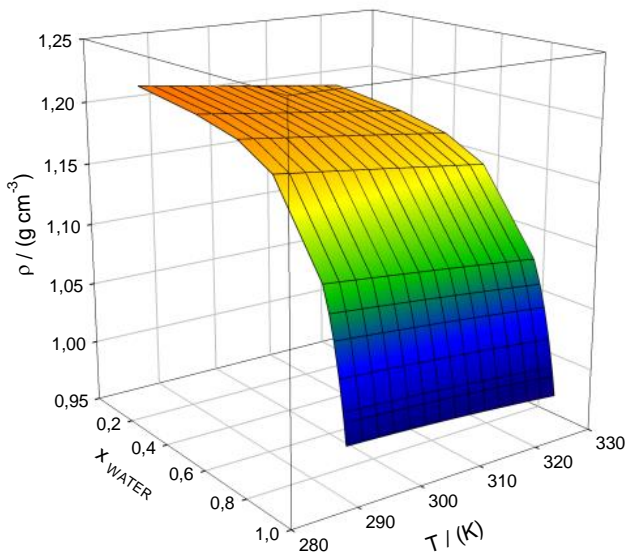

Vol. 21 (No. 2) / 72 
(b)

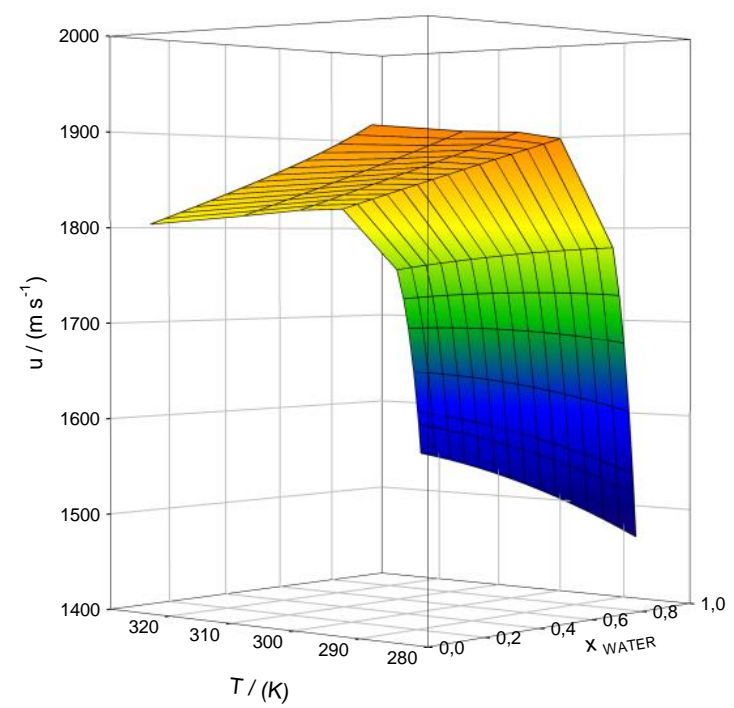

(c)

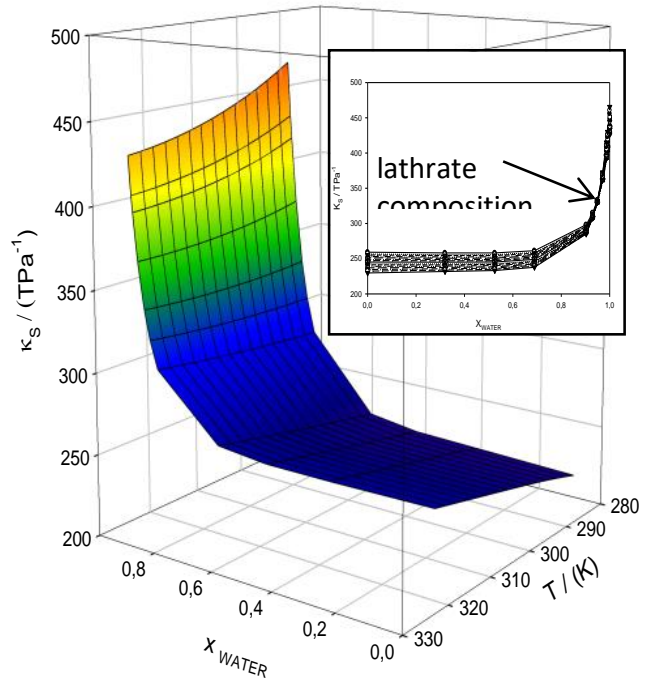

Figure 1. Surfaces of (a) density $\left(\mathrm{gcm}^{-3}\right)$, (b) ultrasonic velocity $\left(\mathrm{ms}^{-1}\right)$ and $(\mathrm{c})$ isentropic compressibility $\left(\mathrm{TPa}^{-1}\right)$ for 2-hydroxy ethylammonium lactate (2-HEAL)+water mixture at the range of temperatures 288.15-323.15 K.

\subsection{Derived Properties Correlation}

In order to estimate the non-ideality of these mixtures, the excess molar volumes and changes of isentropic compressibilities were computed by means of Eq. 3:

$\delta Q_{i j}=Q-\sum_{i=1}^{N} x_{i} Q_{i}$

where $\delta Q_{i j}$ is variation of a magnitude $Q$ ( $V^{E}$, excess molar volumes and $\delta \kappa_{S}$, changes of isentropic compressibilities), $Q$ is the pure solvent magnitude (molar volume or isentropic compressibility), $x_{i}$ is mole fraction, and $N$ is the number of components. A modified Redlich-Kister type equation was used to correlate the derived properties, by the unweighted least squares method, all experimental points weighting equally:

$\delta Q_{i j}=x_{i} x_{j}\left(\sum_{p=o}^{m}\left(x_{i}-x_{j}\right) \cdot\left(\sum_{i=0}^{2} C_{i p} T^{i}\right)\right)$

where $\delta Q_{i j}$ stands for the derived magnitude, $C_{i p}$ are the fitting parameters and $m$ is the degree of the polynomial, determined applying the F-test due to Bevington. The $C_{i p}$ parameters were computed using a non-linear optimization algorithm due to Marquardt (Table 3).

(a)

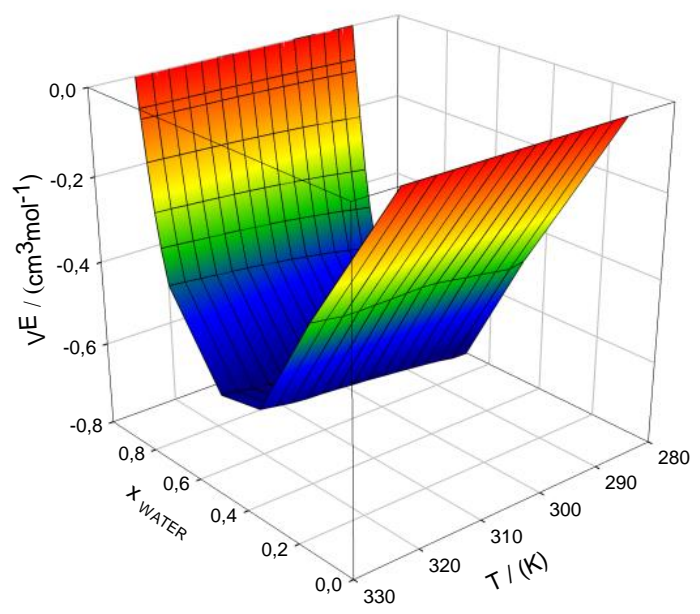

(b)

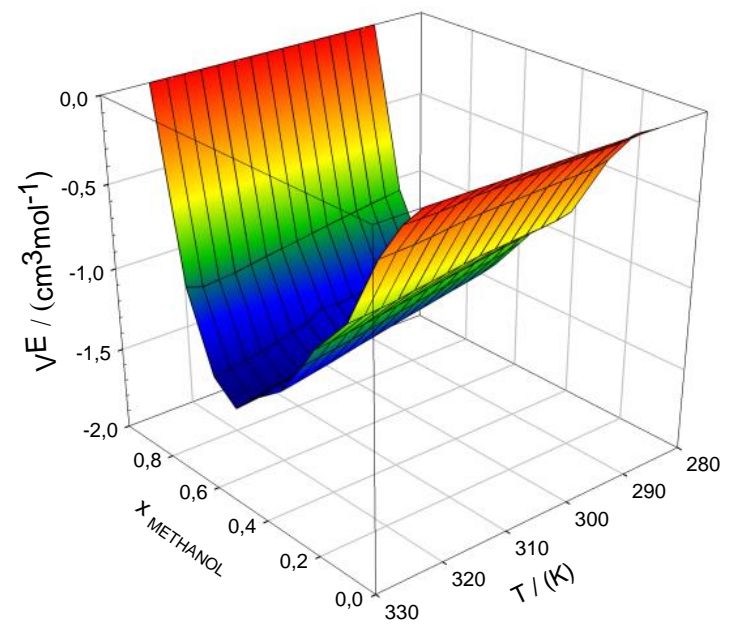

(c)

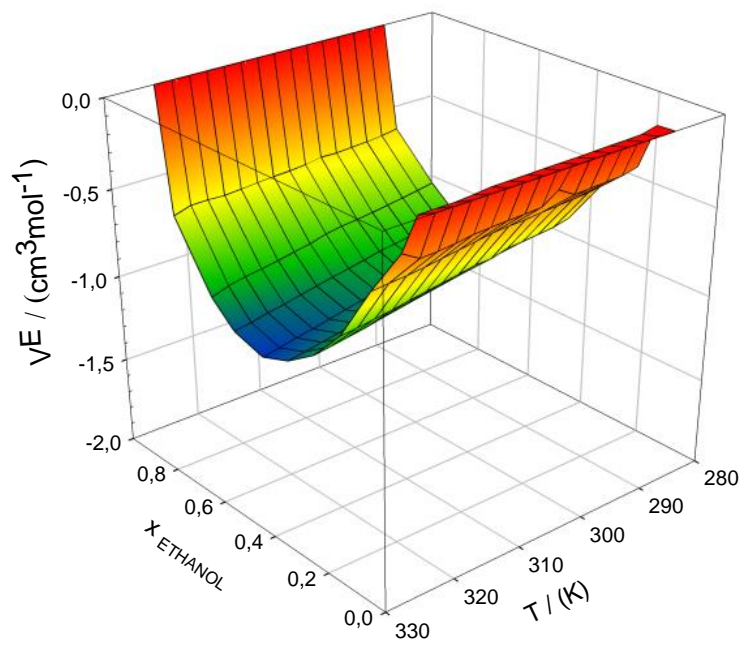

Figure 2. Surfaces of excess molar volumes $\left(\mathrm{cm}^{3} \mathrm{~mol}^{-1}\right)$ of 2hydroxy ethylammonium lactate $(2-H E A L)+(a)$ water, $(b)$ methanol and (c) ethanol mixture at the range of temperatures 288.15-323.15 $\mathrm{K}$. 
In the corresponding figures of these derived properties, a strong contractive tendency is showed for all cases, showing the lower values (higher negative values) those mixtures containing methanol and ethanol. Surprisingly, aqueous mixtures volumetric behaviour is analogous in trend but the contraction capability of this mixture is the lowest due to a lower solvent molecule volume, strong polar character and steric hindrance with ions aliphatic ends. At any case, the most negative values were observed at almost equimolar compositions and the highest temperatures for alcohols and the lowest temperature for water (Figure 2).

This fact reveals as the increase of kinetics on water molecules produces an increase of potency hydrogen bond and thus a considerable diminution of interaction among ions and dipoles. Aqueous mixtures show a slightly increasing tendency on temperature dependence, in terms of change of isentropic compressibility. This fact is gathered as an increasing negative tendency as temperature rises for alcohols and contrary for aqueous mixtures. For both derived magnitudes, the most non-ideal trend was observed for methanol and minima at equimolar composition.

\subsection{Apparent Molar Magnitudes Correlation}

The apparent molar volumes $\left(\phi_{V}, \mathrm{~cm}^{3} \mathrm{~mol}^{-1}\right)$ of 2-HEAL in solvents are calculated from the volumetric values by the following equation:

$\varphi_{V}=1000 \cdot\left(\frac{\rho_{\text {solv }}-\rho}{m \cdot \rho \cdot \rho_{\text {solv }}}\right)+\frac{M_{\text {solv }}}{\rho}$ where $\rho$ is the density of solution, $\rho_{\text {solv }}$ is the density of the hydroxylic solvent at the same temperature, $\mathrm{m}$ is the molality of the solution and $\mathrm{M}_{\mathrm{PIL}}$ is the molar mass of the protic ionic liquid 2-HEAL (Table 1). The isentropic apparent molar compressibilities $\left(\phi_{\kappa S}, \mathrm{~cm}^{3} \mathrm{~mol}^{-1} \mathrm{TPa}^{-1}\right)$ are computed from density and ultrasonic velocities using the following equation:

$\varphi_{\kappa S}=1000 \cdot\left(\frac{\kappa_{S}-\kappa_{S s o l v}}{m \cdot \rho}\right)+\kappa_{S} \cdot \varphi_{V}$

where $\kappa_{S}$ is the isentropic compressibility of solution, $\kappa_{S s o l v}$ is the isentropic compressibility of the hydroxylic solvent at the same temperature, and the other symbols express the same meaning as indicated above. These apparent magnitudes were correlated by a modified Redlich-Mayer equation as follows:

$\varphi_{V}=\left(\sum_{i=0}^{n} \varphi_{V 0 i}^{0} T^{i}\right)+\sum_{p=0}^{n}\left(\sum_{i=0}^{2} J_{i p} T^{i}\right) \cdot m^{\left(\frac{i+1}{2}\right)}$

$\varphi_{\kappa S}=\left(\sum_{i=0}^{n} \varphi_{\kappa S 0 i}^{0} T^{i}\right)+\sum_{p=0}^{m}\left(\sum_{i=0}^{2} K_{i p} T^{i}\right) \cdot m^{\left(\frac{i+1}{2}\right)}$

where $J_{i p}, K_{i p}$ and $\phi_{V_{0 i}}^{0}$ and $\phi_{\kappa_{S_{0 i}}}^{0}$ are fitting temperature dependent parameters (Table 4), which were computed as explained previously. For example, Figure 3 shows the apparent molar volumes of the 2-HEAL+hydroxylic solvents mixtures.

Table 3. Fitting parameters of Eq. 4 and root mean square deviations $(\sigma)$ for excess molar volumes and changes of isentropic compressibilities for 2-HEAL+(water, methanol or ethanol) at $288.15-323.15 \mathrm{~K}$

\begin{tabular}{|c|c|c|c|c|c|c|}
\hline & \multicolumn{2}{|c|}{ 2-HEAL+water } & \multicolumn{2}{|c|}{ 2-HEAL+methanol } & \multicolumn{2}{|c|}{ 2-HEAL+ethanol } \\
\hline & $\begin{array}{c}\mathrm{V}^{\mathrm{E}} \\
/\left(\mathrm{cm}^{3} \mathrm{~mol}^{-1}\right) \\
\end{array}$ & $\begin{array}{c}\delta \kappa \mathrm{s} \\
/\left(\mathrm{TPa}^{-1}\right)\end{array}$ & $\begin{array}{c}\mathrm{V}^{\mathrm{E}} \\
/\left(\mathrm{cm}^{3} \mathrm{~mol}^{-1}\right) \\
\end{array}$ & $\begin{array}{c}\delta \kappa \mathrm{s} \\
/\left(\mathrm{TPa}^{-1}\right)\end{array}$ & $\begin{array}{c}\mathrm{V}^{\mathrm{E}} \\
/\left(\mathrm{cm}^{3} \mathrm{~mol}^{-1}\right) \\
\end{array}$ & $\begin{array}{c}\delta \kappa s \\
/\left(\mathrm{TPa}^{-1}\right) \\
\end{array}$ \\
\hline $\mathrm{C}_{00}$ & -5.185737 & -5709.4749 & 9.8957 & -3178.3623 & 5.2256 & -1357.0985 \\
\hline $\mathrm{C}_{01}$ & 0.0106 & 29.4747 & -0.0660 & 24.9338 & -0.0336 & 12.7438 \\
\hline $\mathrm{C}_{02}$ & $-7.6738 \mathrm{E}-6$ & -0.0417 & $5.7084 \mathrm{E}-5$ & -0.0621 & $8.1600 \mathrm{E}-6$ & -0.0380 \\
\hline $\mathrm{C}_{10}$ & -13.0903 & 5468.2406 & -6.3020 & -3634.7626 & 6.6125 & -1225.8719 \\
\hline $\mathrm{C}_{11}$ & 0.0731 & 0.0000 & 0.0285 & 27.6472 & -0.0514 & 11.6372 \\
\hline $\mathrm{C}_{12}$ & $-1.0370 \mathrm{E}-4$ & -0.0408 & $-6.9912 E-5$ & -0.0628 & $-7.1802 \mathrm{E}-5$ & -0.0314 \\
\hline $\mathrm{C}_{20}$ & -70.8198 & -40523.9301 & -149.6608 & -5517.9950 & -107.2362 & -6798.2927 \\
\hline $\mathrm{C}_{21}$ & 0.4431 & 181.254603 & 0.9717 & 39.0651 & 0.7184 & 46.2563 \\
\hline $\mathrm{C}_{22}$ & -5.1857 & -0.1957 & $-1.6207 \mathrm{E}-3$ & -0.0761 & $-1.1858 \mathrm{E}-3$ & -0.0805 \\
\hline $\mathrm{C}_{30}$ & $-7.0005 \mathrm{E}-4$ & -58519.6341 & -35.8831 & -3398.8559 & -78.9828 & -8149.6309 \\
\hline $\mathrm{C}_{31}$ & 94.9267 & 118.4407 & 0.2669 & 26.4254 & 0.5752 & 53.0657 \\
\hline $\mathrm{C}_{32}$ & -0.6897 & 0.1286 & $-5.0260 \mathrm{E}-4$ & -0.0558 & $-9.8671 \mathrm{E}-4$ & -0.0857 \\
\hline $\mathrm{C}_{40}$ & $1.1257 \mathrm{E}-3$ & 290961.7594 & 283.8615 & -2076.3444 & 157.261639 & 16854.9919 \\
\hline $\mathrm{C}_{41}$ & -46.3664 & -1186.3399 & -1.8492 & 20.3504 & -1.067288 & -106.2830 \\
\hline $\mathrm{C}_{42}$ & 0.4105 & 1.0657 & $3.0276 \mathrm{E}-3$ & -0.0534 & $1.735530 \mathrm{E}-3$ & 0.1611 \\
\hline $\mathrm{C}_{50}$ & $-6.7582 \mathrm{E}-4$ & -261548.8910 & 187.6395 & -632.1514 & 71.173004 & 19898.673841 \\
\hline $\mathrm{C}_{51}$ & -31.0102 & 1254.2638 & -1.2807 & 7.6074 & -0.557827 & -125.140953 \\
\hline $\mathrm{C}_{52}$ & 0.1387 & -1.4988 & $2.1530 \mathrm{E}-3$ & -0.0247 & $9.275909 \mathrm{E}-4$ & 0.189088 \\
\hline$\sigma$ & $2.807 \mathrm{E}-3$ & 0.298 & $2.212 \mathrm{E}-2$ & 0.709 & 2.472 E-3 & 1.623 \\
\hline
\end{tabular}


(a)

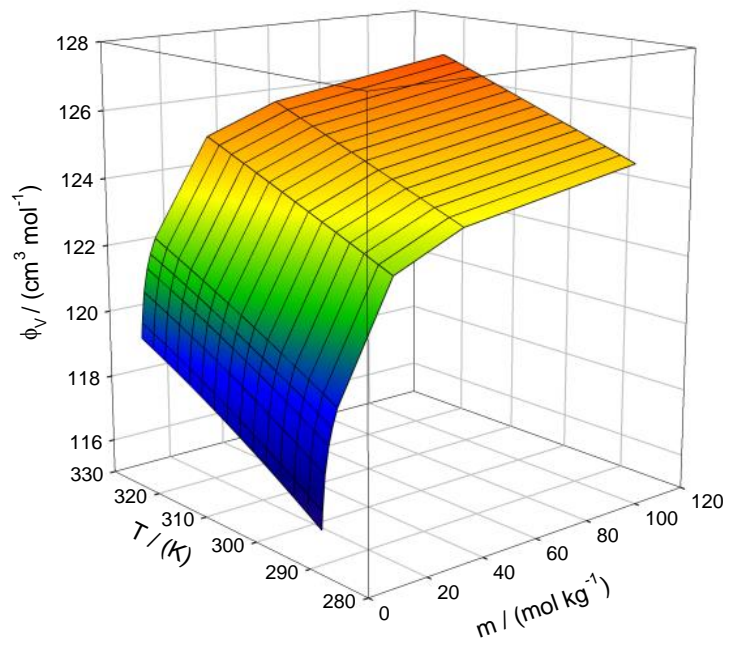

(b)

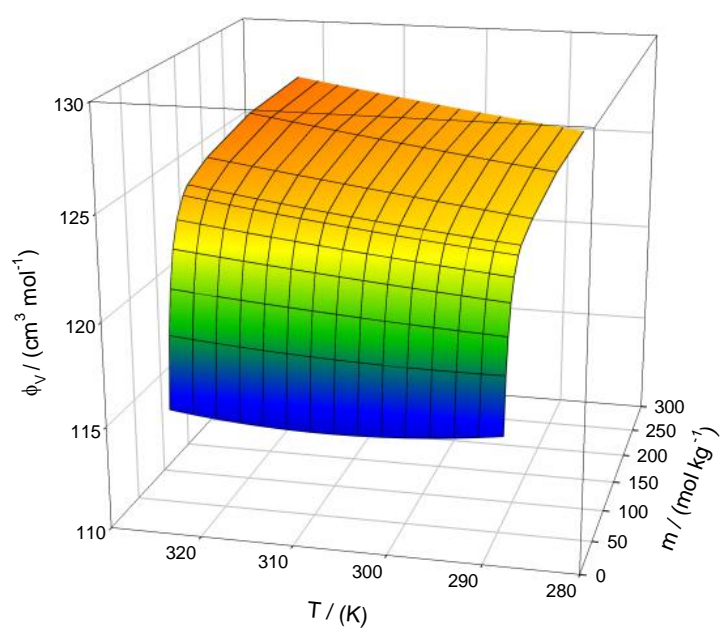

(c)

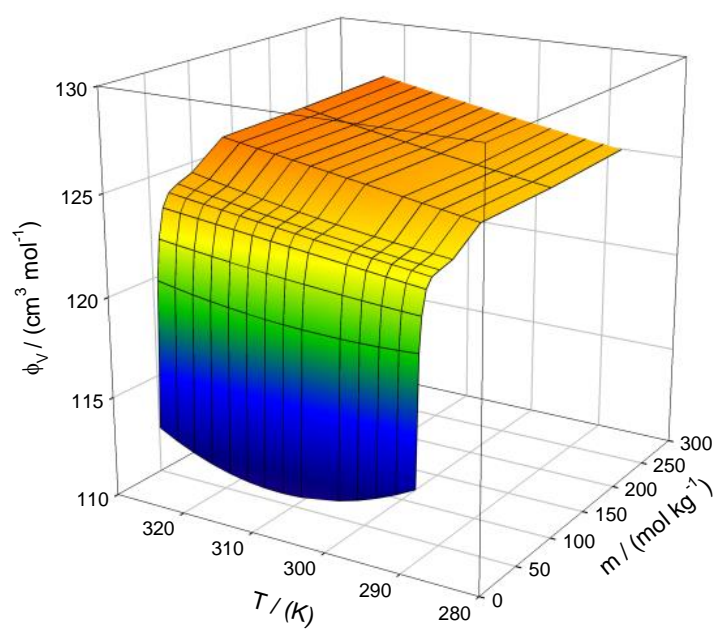

Figure 3. Surfaces of apparent molar volumes $\left(\phi_{V}, \mathrm{~cm}^{3} \mathrm{~mol}^{-}\right.$ $\left.{ }^{1}\right)$ of 2-hydroxy ethylammonium lactate (2-HEAL) and its solutions with short hydroxylic solvents, (a) water, (b) methanol and (c) ethanol at the range of temperatures $288.15-323.15 \mathrm{~K}$.
From these expressions, the limiting values for apparent molar volumes (indicated with superscript zero) were computed showing increasing tendency for mixtures which compounds gathering more methylene groups (water with zero $\mathrm{CH}_{2}$ groups). Almost linear temperature dependence also should be observed, as well as a progressive decreasing slope from water (positive tendency) towards methanol (negative tendency) (Figure 4).

As observed in Figure 4, empirical $\phi_{V_{0 i}}^{0}$ values for the aqueous mixture are higher than the corresponding for alcoholic components at all studied temperatures. This means that the ion + water interaction is stronger than the ion + ion interactions into the protic ionic liquid. This effect in methanolic and ethanolic solutions is inversed. At the same time, the dependence of temperature for water and alcoholic solutions are also inversed.

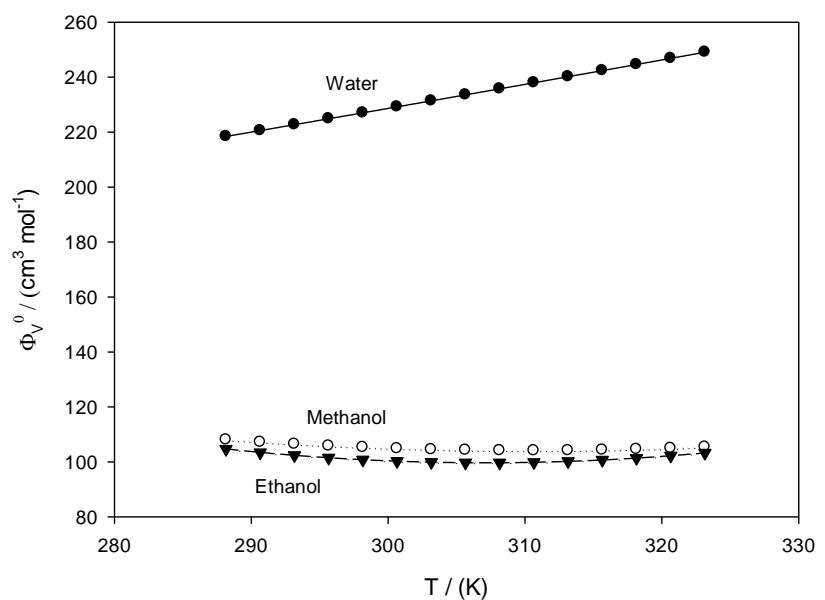

Figure 4. Curves of apparent molar volumes at infinite dilution $\left(\mathrm{cm}^{3} \mathrm{~mol}^{-1}\right)$ of 2-hydroxy ethylammonium lactate (2HEAL)+short hydroxylic solvents, $(\bullet)$ water, (०) methanol and $(\boldsymbol{\nabla})$ ethanol at $288.15-323.15 \mathrm{~K}$.

At infinite dilution, each ion is surrounded only by the corresponding solvent molecules and is infinitely distant with the other ions. It follows that the apparent molar volume at infinite dilution is unaffected by interaction among ions and then is a sharp pure measurement of ion + solvent interaction.

Figure 4 shows that the limiting apparent molar volumes, for 2-HEAL in water system at different temperatures are greater than the corresponding values for alcoholic mixtures.

\subsection{Isobaric Expansibility}

A frequently applied derived magnitude for industrial mixtures is the temperature dependence of volumetry which is expressed as isobaric expansibility or thermal expansion coefficient $(\alpha)$. The data reported in literature normally give only values of thermal expansion coefficients both of pure compounds and its mixtures, showing the relative changes in density, calculated by means of $(-\Delta \rho / \rho)$ as a function of temperature and assuming that $\alpha$ remains constant in any thermal range. As in the case of pure chemicals it can be computed by way of the expression:

$\alpha=-\left(\frac{\partial \ln \rho}{\partial T}\right)_{P, x}$ 
taking into account the temperature dependence of density. The isobaric expansibility diminishes abruptly towards pure solvent, at any case, for aqueous mixture (slighter for higher temperature). The effect of temperature is opposite for alcoholic mixtures, increasing expansibility as solvent composition rises. Both aqueous and alcoholic mixtures offer similar tendency, showing progressively rising values when temperature is increased (Figure 5).

\subsection{Isothermal Coefficient of Pressure Excess Molar Enthalpy}

The isothermal coefficient of pressure excess molar enthalpy can be derived accurately from volumetric measurements by application of the following expression:

$$
\left(\frac{\partial H^{E}}{\partial P}\right)_{T, x}=V^{E}-T\left(\frac{\partial V^{E}}{\partial T}\right)_{P, x}
$$

this magnitude stands for the dependence of excess molar enthalpy of mixing with pressure at fixed composition and temperature. The aqueous mixture shows the most negative values for the isothermal coefficient. The influence of decreasing temperature produces lower negative values only for aqueous system, as observed at Figure 6.

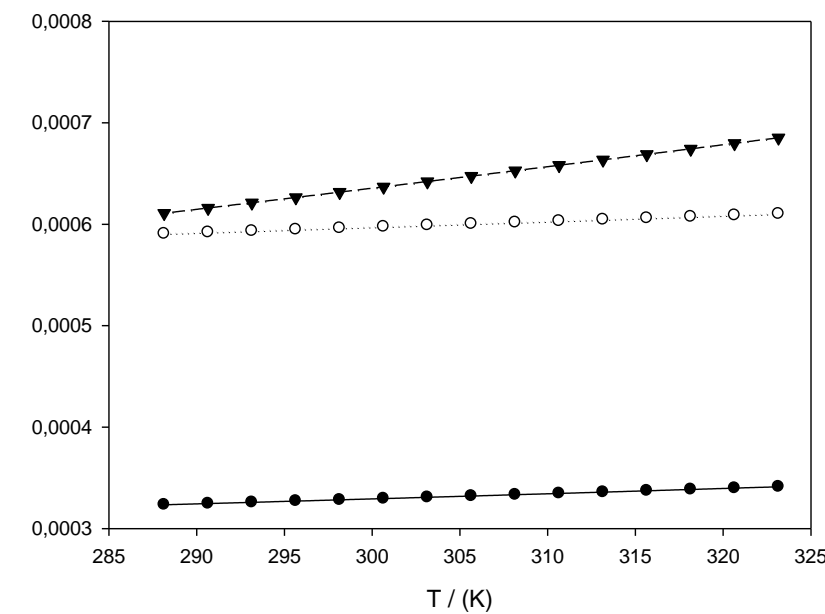

Figure 5. Curves of isobaric expansibility $\left(K^{-1}\right)$ at equimolar composition of 2-hydroxy ethylammonium lactate (2-HEAL) and its solutions with short hydroxylic solvents, (•) water, (०) methanol and $(\boldsymbol{\nabla})$ ethanol at the range of temperatures $288.15-323.15 \mathrm{~K}$.

Table 4. Fitting parameters of Eqs. 7-8 at 288.15-323.15 K and root mean square deviations ( $\sigma$ ) for apparent molar volumes and apparent molar isentropic compressibilities for the mixtures 2-HEAL and the corresponding solvent.

\begin{tabular}{|c|c|c|c|c|c|c|c|}
\hline & Water & Methanol & Ethanol & & Water & Methanol & Ethanol \\
\hline & $\begin{array}{c}\Phi_{\mathrm{V}} \\
/\left(\mathrm{cm}^{3} \mathrm{~mol}^{-1}\right) \\
\end{array}$ & $\begin{array}{c}\Phi_{\mathrm{V}} \\
/\left(\mathrm{cm}^{3} \mathrm{~mol}^{-1}\right) \\
\end{array}$ & $\begin{array}{c}\Phi_{\mathrm{V}} \\
/\left(\mathrm{cm}^{3} \mathrm{~mol}^{-1}\right) \\
\end{array}$ & & $\begin{array}{c}\mathrm{K}_{\Phi \mathrm{S}} \\
/\left(\mathrm{TPa}^{-1} \mathrm{~cm}^{3} \mathrm{~mol}^{-1}\right) \\
\end{array}$ & $\begin{array}{c}\mathrm{K}_{\Phi \mathrm{S}} \\
/\left(\mathrm{TPa}^{-1} \mathrm{~cm}^{3} \mathrm{~mol}^{-1}\right)\end{array}$ & $\begin{array}{c}\mathrm{K}_{\Phi \mathrm{S}} \\
/\left(\mathrm{TPa}^{-1} \mathrm{~cm}^{3} \mathrm{~mol}^{-1}\right)\end{array}$ \\
\hline$\overline{\mathbf{J}_{00}}$ & 19.9378 & -502.4984 & -971.7263 & $\mathrm{~K}_{00}$ & 970443.1382 & -302770.52 & -1493423.62 \\
\hline $\mathbf{J}_{01}$ & -0.0833 & 3.2885 & 6.4213 & $\mathrm{~K}_{01}$ & -5385.8314 & 741.4371 & 8356.5002 \\
\hline $\mathrm{J}_{02}$ & $1.1664 \mathrm{E}-4$ & $-5.2911 \mathrm{E}-3$ & -0.0104 & $\mathrm{~K}_{02}$ & 7.7723 & 2.4692 & -9.6118 \\
\hline $\mathrm{J}_{10}$ & -0.8730 & 126.2493 & 264.7915 & $\mathrm{~K}_{10}$ & -79820.6646 & 212569.49 & 683529.895 \\
\hline $\mathrm{J}_{11}$ & -0.0133 & -0.8256 & -1.7510 & $\mathrm{~K}_{11}$ & -45.5609 & -1053.9012 & -4027.2108 \\
\hline $\mathrm{J}_{12}$ & $2.9106 \mathrm{E}-5$ & $1.3355 \mathrm{E}-3$ & $2.8491 \mathrm{E}-3$ & $\mathrm{~K}_{12}$ & 0.6428 & 0.7155 & 5.2872 \\
\hline $\mathbf{J}_{20}$ & $-1.7643 \mathrm{E}-4$ & -14.4982 & -32.3537 & $\mathrm{~K}_{20}$ & -90677.7895 & -48804.026 & -141280.987 \\
\hline $\mathbf{J}_{21}$ & 4.8049E-3 & 0.0948 & 0.2140 & $\mathrm{~K}_{21}$ & 813.9641 & 270.5782 & 850.3162 \\
\hline $\mathbf{J}_{22}$ & $-9.8931 \mathrm{E}-6$ & $-1.5372 \mathrm{E}-4$ & $-3.4859 \mathrm{E}-4$ & $\mathrm{~K}_{22}$ & -1.5426 & -0.2949 & -1.1718 \\
\hline $\mathbf{J}_{30}$ & -0.0166 & 0.7593 & 1.7834 & $\mathrm{~K}_{30}$ & 30215.2893 & 5131.3654 & 14480.9506 \\
\hline $\mathbf{J}_{31}$ & $-4.4020 \mathrm{E}-4$ & $-4.9626 \mathrm{E}-3$ & -0.0118 & $\mathrm{~K}_{31}$ & -243.4649 & -29.7180 & -88.1038 \\
\hline $\mathbf{J}_{32}$ & $9.6760 \mathrm{E}-7$ & $8.0610 \mathrm{E}-6$ & $1.9229 \mathrm{E}-5$ & $\mathrm{~K}_{32}$ & 0.4413 & 0.0368 & 0.1243 \\
\hline $\mathrm{J}_{40}$ & $1.2904 \mathrm{E}-3$ & -0.0145 & -0.0358 & $\mathrm{~K}_{40}$ & -3494.3719 & -250.8103 & -710.9386 \\
\hline $\mathrm{J}_{41}$ & $1.3523 \mathrm{E}-5$ & $9.4967 \mathrm{E}-5$ & $2.3714 \mathrm{E}-4$ & $\mathrm{~K}_{41}$ & 27.3653 & 1.4851 & 4.3521 \\
\hline \multirow[t]{4}{*}{$\mathrm{J}_{42}$} & $-3.2341 \mathrm{E}-8$ & $-1.5440 \mathrm{E}-7$ & $-3.8650 \mathrm{E}-7$ & $\mathrm{~K}_{42}$ & -0.0490 & $-1.9440 \mathrm{E}-3$ & $-6.2214 \mathrm{E}-3$ \\
\hline & & & & $\mathrm{K}_{50}$ & 136.6891 & 4.5662 & 13.2164 \\
\hline & & & & $\mathrm{K}_{51}$ & -1.0579 & -0.0274 & -0.0812 \\
\hline & & & & $\mathrm{K}_{52}$ & $1.8834 \mathrm{E}-3$ & $3.6937 \mathrm{E}-5$ & $1.1700 \mathrm{E}-4$ \\
\hline$\Phi_{\mathrm{v} 00}^{0}$ & 24.9987 & 868.8728 & 1410.3147 & $\kappa_{\Phi S 00}^{0}$ & -1693870.04 & -225921.65 & 990915.007 \\
\hline$\Phi_{\mathrm{v} 00}^{0}$ & 0.4887 & -4.9291 & -8.5365 & $\kappa_{\Phi S 00}^{0}$ & 9968.5430 & 3578.6932 & -4386.2097 \\
\hline$\Phi_{\mathrm{v} 00}^{0}$ & $-6.3355 \mathrm{E}-4$ & $7.9387 \mathrm{E}-3$ & 0.0139 & $\kappa_{\Phi S 00}^{0}$ & -14.8122 & -11.6443 & 1.7432 \\
\hline$\sigma$ & 0.173 & 0.096 & 0.402 & $\sigma$ & 199.611 & 153.418 & 560.909 \\
\hline
\end{tabular}


(a)

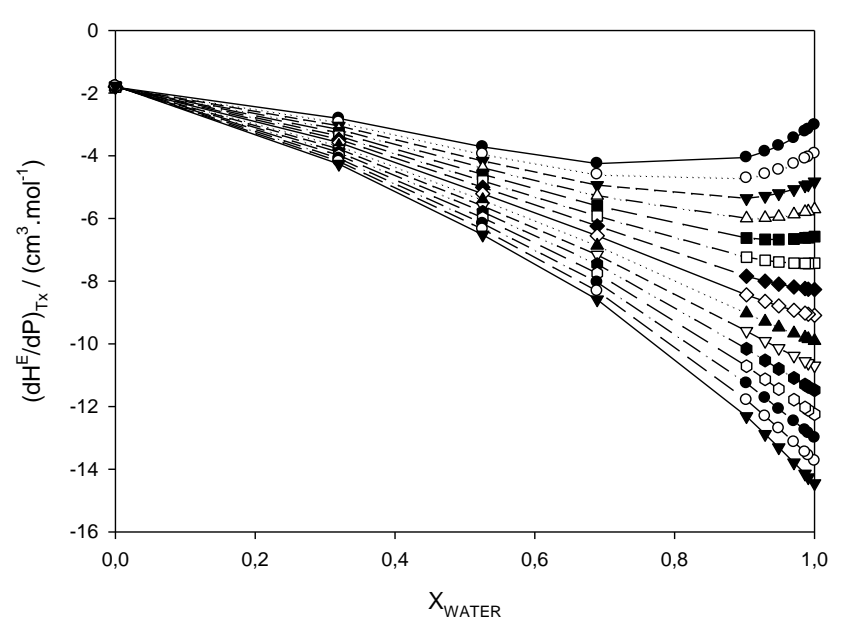

(b)

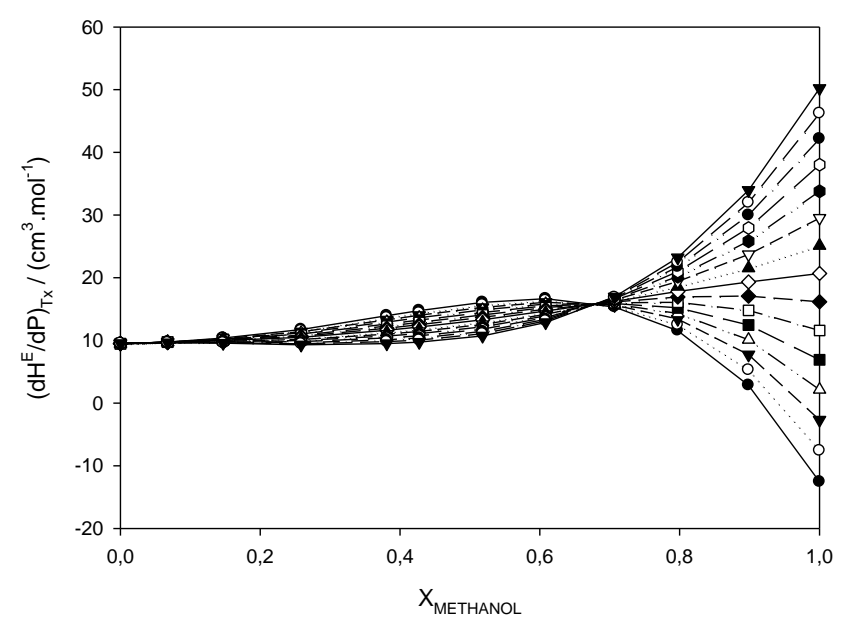

(c)

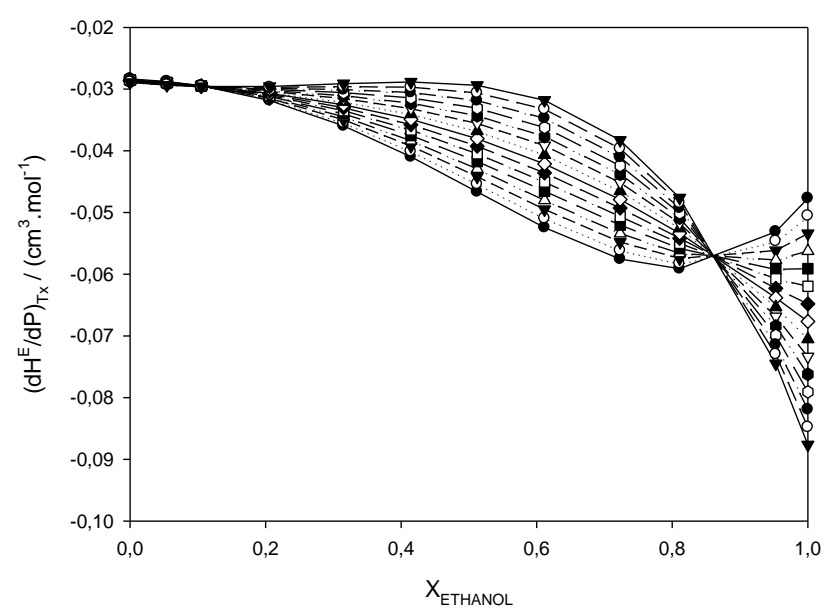

Figure 6. Curves of isothermal coefficient of pressure excess molar enthalpy $\left(\mathrm{cm}^{3} \mathrm{~mol}^{-1}\right)$ of 2-hydroxy ethylammonium lactate (2-HEAL) and its solutions with short hydroxylic solvents, (a) water, (b) methanol and (c) ethanol at the range of temperatures $288.15-323.15 \mathrm{~K}$.

\subsection{Density Prediction: MNM Model and Modified Heller Equation}

Increasingly, modern process design involves the use of computer aided process design procedures. The physical property packages used in process simulators typically rely on generalized equations for predicting properties as a function of temperature, pressure, etc. Despite the success developing several procedures of density estimation for pure compounds or mixtures, only a few of them may be of real application for chemicals of nonideal trend or high molar mass. The Mchaweh-Nasrifar-Moshfeghian model (MNM Model) is a simplification of the Nasrifar-Moshfeghian liquid density correlation, replacing the Mathias and Copeman temperature-dependent term with the original Soave-Redlich-Kwong equation of state (SRK EOS) temperature-dependent term. This replacement has overcome the limitations in use for the original model which were due to the Mathias and Copeman vapor pressure dependent parameters. The complete description of this model should be found elsewhere [23-24].

The critical properties and acentric factors required were estimated by a group contribution method based on the wellknown concepts of Lydersen and of Joback and Reid, proposed by Valderrama and Robles [33], due to these parameters are not available for the protic ionic liquid (Table $5)$. The other critical values were obtained from open literature [34].

Table 5. Open literature and estimated critical values for compounds enclosed into binary mixtures.

\begin{tabular}{lcccc}
\hline Compound & $\mathrm{P}_{\mathrm{c}}(\mathrm{MPa})$ & $\mathrm{T}_{\mathrm{c}}(\mathrm{K})$ & $\mathrm{Z}_{\mathrm{c}}$ & $\omega$ \\
\hline Water & 22.064 & 647.14 & 0.229 & 0.344 \\
Methanol & 8.10 & 512.6 & 0.224 & 0.565 \\
Ethanol & 6.15 & 513.9 & 0.240 & 0.649 \\
2-HEAL $^{*}$ & 3.93 & 812.6 & 0.322 & 1.357 \\
\hline
\end{tabular}

* Simulated by [33]

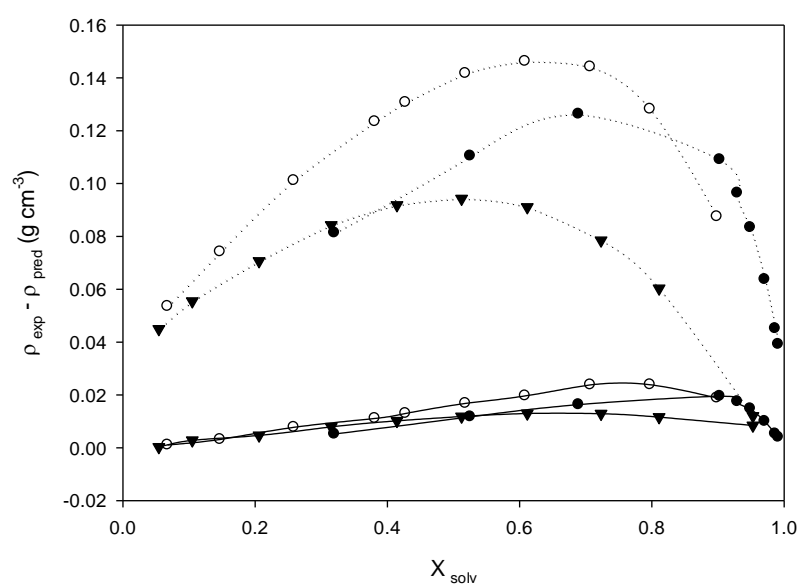

Figure 7. Comparison of experimental and estimated density $\left(\mathrm{gcm}^{-3}\right)$ by Mchaweh-Nasrifar-Moshfeghian (MNM) model (-) and Modified Heller equation (MHE) (...) of 2-hydroxy ethylammonium lactate (2-HEAL) and its solutions with short hydroxylic solvents, $(\bullet)$ water, $(\circ)$ methanol and $(\boldsymbol{\nabla})$ ethanol at $298.15 \mathrm{~K}$.

The modified Heller equation is an emprirical rule for density estimation that has proved its efficiency for complex mixtures [25]. It estimates the volumetric trend of mixtures as a function of temperature, as follows:

$\frac{1}{\rho_{M I X}}=\sum_{i=1}^{N}\left(\frac{\omega_{i}}{\sum_{i=0}^{N} \sum_{j=0}^{M} D_{i j} T^{j}}\right)$

where $i$ stands for the protic ionic liquid or the corresponding solvent into the binary mixture and $\omega_{i}$ stands for the mass 
fraction. Attending to the measured data, the estimation of density was made as function of temperature, so, data at different temperatures for protic ionic liquid and solvents are necessary. The experimental density data of solvent was applied by means a polynomial [35] and for protic ionic liquid, an earlier collection of data published by the authors [36]. In Figure 7, a comparison of the estimated densities is enclosed as a function of temperature for the mixtures. It could be observed as MHE slight over predicts the density values, showing the better results for ethanol and, at any case, at low solvent compositions. Comparatively, MHE offers much better results in terms of deviation than MNM for these mixtures.

\subsection{Ultrasonic Velocity Prediction: Collision Factor Theory}

Ultrasonic velocity has been systematically measured in the last years but this kind of data is scarce yet. Predictive procedures are then of primary interest, the same problems that were observed for density prediction being found. In this work, experimental data for the ultrasonic velocity of the mixtures 2-HEAL+(water, methanol or ethanol) were compared with values determined by Collision Factor Theory Theory (CFT) [26], which are dependent on the collision factors as a function of temperature into pure solvent or mixture. Detailed description of these procedures, the pertinent relations for these calculations and its theoretical basis were described in the literature indicated above.

In what is referred to theoretical estimation, as it could be observed in Figure 8, the better results are showed for the applied model at low or high solvent concentrations, as well as, at low temperatures. A slight overestimation is observed at any case. The better results were for ethanol mixtures at high temperatures, with deviations lower than $5 \%$.

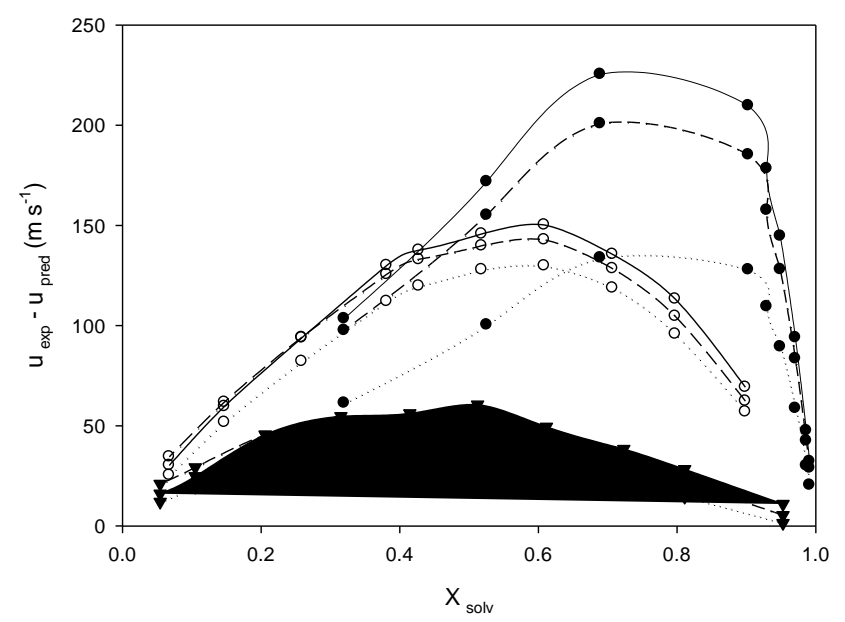

Figure 8. Comparison of experimental and estimated ultrasonic velocity ( $m s-1)$ by Collision Factor Theory of 2hydroxy ethylammonium lactate (2-HEAL) and its solutions with short hydroxylic solvents , (•) water, (०) methanol and ( $\mathbf{\nabla})$ ethanol at $288.15 \mathrm{~K}(-), 298.15 \mathrm{~K}(--\longrightarrow)$ and $323.15 \mathrm{~K}(\cdots \cdots)$.

\section{Conclusions}

As observed in analogous mixtures [14, 18, 21], in the temperature range investigated, the densities are slightly affected by the temperature while ultrasonic velocities decrease dramatically when increasing temperature into the mixtures. The density and ultrasonic velocity shows a detrimental trend for all mixtures. Only pure water gathers an inverse tendency for ultrasonic velocity as a function of temperature, as previously observed.

Attending to the results, it was found: (i) organic compounds have strong effects on the physicochemical properties of protic ionic liquids, specially on their volumetric trend, and the degree of their influence depends on the nature of anion and cation of the ionic liquids, and the nature of the involved organic solvents. All the studied mixtures show total miscibility at the range of temperature (288.15 - 323.15 K). This study highlighted the influence of linear aliphatic chains of solvents in the experimental data presented, that is mainly due to the differences in molecular size and hydrogen bond potency among solvent molecules; (ii) open iceberg structure of water shows a hydrogen bond potency higher than those for short alcohols, although in terms of their volumetric properties, the effect of organic compounds investigated follows the order: water < ethanol < methanol. All these systems show higher densities and ultrasonic velocities that analogous systems with lighter protic ionic liquids [14, 18, 21]. The whole studied cases showed negative trend in terms of excess molar volumes. Ions structure of this protic ionic liquid greatly affects the physicochemical properties of the mixtures as actual development of our studies is showing at our laboratory. In fact, the obtained intersection point in isentropic compressibility isotherms for aqueous 2-HEAL may be an indication of clathrate-like structure formation at dilute solvent compositions, almost at the same point that in aqueous mixtures of other protic ionic liquids (2-hydroxy diethylammonium formate,2-hydroxy diethylammonium acetate and 2-hydroxy diethylammonium lactate). According to open literature, the very narrow interval in which the compressibility isotherms cross one another points to formation of a clathrate-like structure with the stoichiometry corresponding to the concentration at which the crossing occurs. The structure is relatively temperature-resistant and, consequently, its compressibility is almost temperature independent. It should be noted that the crossing interval has been described sometimes as a common crossing point, but that seems imprecise. Since guest molecules of any other hydrogen bond molecule may participate in hydrogen bonding with the host lattice formed by water, the structures may resemble semiclathrates rather than normal clathrates where guest molecule rotates freely into the cage solvent ion. The molecular association becomes maximum at approximately equimolar composition (Figure 4). This may be interpreted due to the formation of strong ion-dipole complex formation producing displacement of electrons and nuclei. The occurrence of maximum velocity is for pure water (low solvent composition) at any temperature and then, a subsequent decrease of velocity with further increase in concentration may be explained by an increment in entropy and a diminution of hydroxyl interaction network by steric hindrance of ions. The progressive awakening of the ion-ion bonds are probably the reason of the strong decrease in ultrasonic velocity. As it could be expected, attending to the molecular structure of solvents, three different trends of interaction could be observed in this kind of mixtures: a hydrogen bond interaction domains high compositions of solvents (clathrate structure for water), ion-dipole interactions domains middle compositions yielding to intense contractive trend at any case and temperature (observe minima in terms of excess molar volumes, Figure $4 \mathrm{a}, \mathrm{b}$ and $\mathrm{c}$, for example), and finally, ion-ion interactions 
domains low compositions (maximum in terms of ultrasonic velocity for water).

Temperature is a fact that in alcohols mixtures deals towards stronger contractive trend, probably due to a better accomodation of the aliphatic ends of ions and solvents by molecular kinetics. In the last few years, different studies have pointed out the special "iceberg structure" of hydroxyl short molecules, and the intense modifications that this structure suffers as a function of composition and temperature into polar media. Protic ionic liquids into this polar media is not an exception. This special structure is specialy sensitive to globular or lineal molecules with polar character, which are difficulty enclosed. Due to that, the short molecules of solvents in mixture, experience greater steric hindrance as compared to the pure solvent situation. Steric hindrance aweakens hydrogen bonding between oxygen and protons into solvents, resulting into formation of short mean life hydrogen bonds and less rigid mixtures at any specific temperature as Figures 1c, 2c, 3c and 5 show.

In what is referred to theoretical estimation, the studied models are, at least, of qualitative accuracy in terms of estimation. Deviations yielded for these magnitudes should be considered as a satisfactory result, supporting their validity as predictive tools, having in mind the high nonideality of these mixtures.

\section{Acknowledgements:}

The authors would like to acknowledge the FAPESB (Fundação de Amparo à Pesquisa do Estado da Bahia, Programa Ação Referência, PET0071/2013 and scientific grant S. M. Barros), and CAPES (Coordenação de Aperfeiçoamento de Pessoal de Nível Superior, scientific grant R.S. Andrade) for their support in developing this research.

\section{Nomenclature}

$\alpha$ - isobaric expansibility or thermal expansion coefficient, $\mathrm{K}^{-1}$

$\delta \kappa_{\mathrm{S}}$ - change of isentropic compressibility on mixing, $\mathrm{TPa}^{-1}$

$\delta \kappa_{\mathrm{S}}$ - isentropic compressibility, $\mathrm{TPa}^{-1}$

$\rho$ - density, $\mathrm{gcm}^{-3}$

$\rho_{\mathrm{c}}-$ critical density, $\mathrm{Kgm}^{-3}$

$B$ - volume of molecule per mole, $\mathrm{m}^{3} \mathrm{~mol}^{-1}$

$H^{\mathrm{E}}$ - excess molar enthalpy, $\mathrm{Jmol}^{-1}$

$n_{\text {DAT }}$ - number of experimental data

$S$ - collision factor

$T_{\mathrm{C}}$ - critical temperature, $\mathrm{K}$

$T_{\mathrm{R}}$ - reduced temperature, $\mathrm{K}$

$u$ - ultrasonic velocity, $\mathrm{m} / \mathrm{s}$

$V$ - mixing molar volume

$V^{\mathrm{E}}$ - excess molar volume, $\mathrm{cm}^{3} \mathrm{~mol}^{-1}$

$\omega-$ acentric factor

$x$ - mole fraction

\section{Appendix}

Experimental data are disposable as supplementary information into Table ST1.

\section{References}

[1] N. V. Plechkova, K. R. Seddon, "Applications of ionic liquids in the chemical industry," Chem. Soc. Rev., 37, 123-150, 2008.
[2] T. L. Greaves, C. J. Drummond, "Protic ionic liquids: Properties and applications," Chem. Rev., 108, 206-237, 2008.

[3] R. Feng, D. Zhao, Y. Guo, "Revisiting characteristics of ionic liquids: A review for further application development," J. Environ. Prot., 1, 95-104, 2010.

[4] J. P. Hallett, T. Welton, "Room-temperature ionic liquids: Solvents for synthesis and catalysis 2," Chem. Rev., 111, 3508-3576, 2011.

[5] G. Khashavar, "A review of ionic liquids, their limits and applications," Green and sustainable chemistry, 4, 044053, 2014.

[6] A. R. Hajipour, F. Rafiee, "Recent progress in ionic liquids and their applications in organic synthesis," Org. Prep. Proced. Int., 47, 001-060, 2015.

[7] T. L. Greaves, C. J. Drummond, "Protic Ionic Liquids: Evolving Structure-Property Relationships and Expanding Applications," Chem. Rev., 115, 1137911448, 2015.

[8] D. Zhao, Y. Liao, Z.D. Zhang, "Toxicity of ionic liquids," Clean-Soil Air Water, 35, 042-048, 2007.

[9] S. Zhu, R. Chen, Y. Wu, Q. Chen, X. Zhang, Z. Yu, “A mini-review on greenness of ionic liquids," Chem. Biochem. Eng. Q. 23, 207-211, 2009.

[10] B. Peric, E. Martí, J. Sierra, R. Cruañas, M. Iglesias, M. A. Garau, "Terrestrial ecotoxicity of short aliphatic protic ionic liquids," Environ. Toxicol. Chem., 30, 2802-2809, 2011.

[11] B. Peric, J. Sierra, E. Martí, U. Bottin-Weber, S. Stolte, "(Eco)toxicity and biodegradability of selected protic and aprotic ionic liquids," J. Hazard. Mater., 261, 099-105, 2013.

[12] B. Peric, J. Siera, E. Martí, R. Cruañas, M. A. Garau, "A comparative study of the terrestrial ecotoxicity of selected protic and aprotic ionic liquids," Chemosphere. 108, 418-425, 2014.

[13] I. Cota, R. Gonzalez-Olmos, M. Iglesias, F. Medina, "New short aliphatic chain ionic liquids: Synthesis, physical properties, and catalytic activity in aldol condensations," J. Phys. Chem. B. 111, 12468-12477, 2007.

[14] M. Iglesias, A. Torres, R. Gonzalez-Olmos, D. Salvatierra, "Effect of temperature on mixing thermodynamics of a new ionic liquid: \{2-Hydroxy ethylammonium formate (2-HEAF) + short hydroxylic solvents \}," J. Chem. Thermodyn. 40, 119-133, 2008.

[15] V. H. Álvarez, S. Mattedi, M. Martin-Pastor, M. Aznar, M. Iglesias, "Synthesis and thermophysical properties of two new protic long-chain ionic liquids with the oleate anion," Fluid Phase Equilib. 299, 354-366, 2010.

[16] V. H. Álvarez, N. Dosil, R. Gonzalez-Cabaleiro, S. Mattedi, M. Martin-Pastor, M. Iglesias, J. M. Navaza, "Brønsted ionic liquids for sustainable processes: Synthesis and physical properties," J. Chem. Eng. Data. 55, 625-632, 2010.

[17] M. Iglesias, R, Gonzalez-Olmos, I. Cota, F. Medina, "Brønsted ionic liquids: study of physico-chemical 
properties and catalytic activity in aldol condensations," Chem. Eng. J., 162, 802-808, 2010.

[18] V. H. Alvarez, S. Mattedi, M. Martin-Pastor, M. Aznar, M. Iglesias, Thermophysical properties of binary mixtures of \{ionic liquid 2-hydroxy ethylammonium acetate + (water, methanol, or ethanol) $\}$," J. Chem. Thermodyn. 43, 997-1010, 2011.

[19] I. Cota, F. Medina, R. Gonzalez-Olmos, M. Iglesias, "Alanine-supported protic ionic liquids as efficient catalysts for aldol condensation reactions," C. R. Chim., 17, 018-022, 2014.

[20] T. Espinosa, M. Jimenez, J. Sanes, A. E. Jimenez, M. Iglesias, M. D. Bermudez, "Low friction with a protic ionic liquid boundary film at the water-lubricated sapphire-stainless steel interface," Tribol. Lett., 53, 001009, 2014.

[21] J. Kulhavy, R. S. Andrade, S. M. Barros, J. S. Serra, M. Iglesias, "Influence of temperature on thermodynamics of protic ionic liquid 2-hydroxy diethylammonium dilactate (2-HDEAL) + short hydroxylic solvents," J. Mol. Liq., 213, 092-106, 2016.

[22] C. Ravazzano, K. Lima, R. S. Andrade, M. Iglesias, "Volumetric and acoustic study of a short protic ionic liquids binary mixture: 2-Hydroxy ethyl ammonium formate (2-HEAF) + 2-Hydroxy diethyl ammonium acetate (2-HDEAA)," Int. J. of Thermo., 19, 244-250, 2016 .

[23] Kh. Nasrifar, Sh. Avatollahi, M. Moshfeghian, "An extended saturated liquid density equation," Fluid Phase Equilib. 166, 163-181, 1999.

[24] A. Mchaweh, A. Alsaygh, Kh. Nasrifar, M. Moshfeghian, "A simplified method for calculating saturated liquid densities," Fluid Phase Equilib. 224, 157-167, 2004

[25] M. Iglesias, B. Orge, M. Domínguez, J. Tojo, “Mixing properties of the binary mixtures of acetone, methanol, ethanol, and 2-butanone at 298.15 K," Phys. Chem. Liq., 37, 009-029, 1998.

[26] C. Gonzalez, M. Iglesias, J. Lanz, G. Marino, B. Orge, J.M. Resa, "Temperature influence on refractive indices and isentropic compressibilities of alcohol (C2C4)+olive oil mixtures", J. Food Eng., 50, 29-40, 2001.
[27] J. A. Riddick, W. B. Bunger, and T. K. Sakano, Organic solvents, Physical properties and methods of purification, $4^{\text {th }} \mathrm{ed}$. New York: Wiley-Interscience, 1997.

[28] TRC Thermodynamic Tables (Thermodynamic Research Center, Texas A\&M University: College Station, TX, 1994).

[29] G. S. Kell, "Density, thermal expansivity, and compressibility of liquid water from $0 . \mathrm{deg}$. to $150 . \mathrm{deg}$.: Correlations and tables for atmospheric pressure and saturation reviewed and expressed on 1968 temperature scale", J. Chem. Eng. Data, 20, 97-105, 1975.

[30] V. A. Del Grosso, C. W. Mader, "Speed of sound in pure water," J. Acoustical Soc. American, 52, 1442, 1972.

[31] J. M. Resa, C. Gonzalez, J. M. Goenaga, "Density, Refractive Index, Speed of Sound at $298.15 \mathrm{~K}$, and Vapor-Liquid Equilibria at $101.3 \mathrm{kPa}$ for Binary Mixtures of Propanol + 2-Methyl-1-butanol and Propanol + 3-Methyl-1-butanol,' J. Chem. Eng. Data, 50, 1570-1575, 2005.

[32] H. Iloukhani, B. Samiey, M. A. Moghaddasi, "Speeds of sound, isentropic compressibilities, viscosities and excess molar volumes of binary mixtures of methylcyclohexane + 2-alkanols or ethanol at T=298.15 K," J. Chem. Thermodyn. 38, 190-200, 2006.

[33] J. O. Valderrama, P. A. Robles, "Critical properties, normal boiling temperatures, and acentric factors of fifty ionic liquids," Ind. Eng. Chem. Res. 46, 1338-1344, 2007.

[34] R.L. Rowley, W.V. Wilding, J.L. Oscarson, Y. Yang, N.F. Giles, DIPPR Data Compilation of Pure Chemical Properties (Design Institute for Physical Properites, AIChE, New York, 2009).

[35] M. Iglesias, R. S. Andrade, A. V. P. Xavier, "Modelling and experimental thermodynamic data of hydroxylic compounds", Monatsh. Chem. 2017. Submitted for publication.

[36] M. Iglesias, R.S. Andrade, C. González, Effect of temperature on thermodynamic properties of new protic ionic liquids, Phys. Chem. Liq. 2017. Submitted for publication. 